\section{俩 Heighten Science \\ P U B L I C I T I O N S Corporation ISSN \\ 2575-0186}

\title{
Radiofrequency ablation for snoring and sleep apnoea
}

\author{
Shah Neha* \\ ENT, Private Practice, Mumbai, India
}

*Address for Correspondence: Shah Neha, ENT, Private Practice, General ENT /OSA/ Radiofrequency, M Dalvi, St. Eliz, Cumballa Hill Hospitals, Mumbai, India, Tel: +91 9820803214; Email: drnehashah@hotmail.com;

clinicalent@yahoo.com

Submitted: 04 April 2019

Approved: 04 June 2019

Published: 05 June 2019

Copyright: @ 2019 Neha S. This is an open access article distributed under the Creative Commons Attribution License, which permits unrestricted use, distribution, and reproduction in any medium, provided the original work is properly cited

D) Check for updates

\section{Aim}

Radiofrequency proves to be a useful tool for snoring/ sleep apnoea cases. Its advantage includes relative precision in incision making, relative bloodless fields if used appropriately, decrease postoperative pain and excellent healing with fibrosis which aids in stiffening tissues.

Radiofrequency is high frequency alternating current used to ablate (cut/coagulate) tissues. It can be applied to nasal turbinates, soft palate, tongue base, tonsils etc. and it can be used to perform various procedures in the cutting mode to improve obstructive sleep disordered breathing.

The objective/aim was to assess efficacy of radiofrequency as a tool for procedures/ surgeries for snoring/ sleep apnoea.

The parameters assessed were post-op pain, post- op blood loss, reduction in subjective snoring sounds by patients and partner, reduction in AHI post operatively.

\section{Methods}

The procedures were carried out over a period of three years. All cases that came to us had complaints of snoring, difficulty in breathing and sleep disturbances at the hospital departments were included in the study. A total of 25 cases were studied. A thorough history, clinical examination in all and flexible endoscopy /sleep study were carried out according to the case.

The radiofrequency SUTTER BM 7180 machine was used to treat patients. The power settings used were from 2 - 6 in the cutting and coagulation mode.

The procedures were carried out under; local or general anaesthesia with oral intubation and a throat pack.

\section{RF tonsillectomy}

Exposing the tonsil on either side, the To-bite radiofrequency forceps or the RF needle was used to incise /open the plane for tonsillar dissection. Dissection was carried out with the same achieving haemostasis at the same time. If properly done bleeding was minimal and pain scores were low post operatively. Fossa deepened and stiffened post operatively. RF setting of 2-3 in cutting mode and 5-6 in coagulation mode was used.

\section{RF Adenoidectomy}

Can be performed after retracting lower edge of the palate with tongue depressors or touniquets and coagulating the adenoid with bipolar forceps, the lower edge of 
the adenoid can be dissected using RF needle or ball point. Bleeding is negligible and wound heals well. There was no case of postoperative haemorrhage. Ideal for recurrent adenoids. RF setting of 5-6 in the coagulation mode.

\section{RF Palate}

It is temperature controlled RF volumetric reduction of the palate in order to stiffen or scar the soft palate. The Sutter RF bipolar probe is used to deliver energy to the soft palate at various points. Blanching has to be avoided. The subsequent stiffening occurs over 6 weeks. It was done under local anaesthesia as an outpatient procedure with no bleeding and low pain scores. Subjective decrease in snoring was achieved even in one sitting.

\section{RF tongue base}

It is temperature controlled volumetric tongue base reduction by giving RF energy to multiple sites of post tongue base with Sutter RF bipolar forceps. Three sittings of reduction gave a significant reduction in tongue base tissue. There was no incidence of tongue base oedema or infection. The procedure could be done under local or general anaesthesia.

\section{RF up3}

It is achieved by uvular and parauvular lateral cuts and trimming of lower edge soft palate with RF in cutting mode and subsequent suturing and tonsillectomy with pillar suturing. The postoperative widening contracture /stiffening helps in achieving a good result.

\section{RAUP}

For snoring is done by uvular and lateral cuts, and redefining the post pillars. Tonsillectomy may be combined. It achieves its result due to removal of the redundant mucosa and subsequent healing with fibrosis. Subjective decrease in snoring is achieved by most patients. RF is used in the cutting mode.

\section{Results}

Results of the study

\begin{tabular}{|c|c|c|c|c|}
\hline Procedure & No of cases & Pain scores & Bleeding intra op & Postop bleeding \\
\hline RF palate & 5 & $4-2$ pts, $1-3$ pts & Nil & Nil \\
\hline RAUP & 6 & $4-1 \mathrm{pt}, 3-1 \mathrm{pt}$ & Negligible & Nil \\
\hline RF tonsils & 6 & $5-2 \mathrm{pt}$ & $10 \mathrm{ml} 3$ pts nil 3 pt & Nil \\
\hline RF adenoids & 4 & $0-4 \mathrm{pts}$ & Nil & Nil \\
\hline RF up3 & 2 & $4-5$ both pts & Nil & Nil \\
\hline RF tongue base & 4 & $0-1$ all pts & \\
\hline
\end{tabular}

\section{Discussion}

Of the 27 patients who underwent treatment with radiofrequency, of the 5 palate cases 2 patients got a pain score of 4 and 3 patients $0-1$. RAUP patients had a varied score of 1 to 4 . RF adenoidectomy was relatively pain free and tonsillectomy was between 4-5. RF tongue base had very low pain scores. There was no postoperative bleeding in any of the cases. Intra operative bleeding was encountered in tonsillectomy when Rf was used in the cutting mode. RF Palate in one sitting can give a reduction in snoring by $50-70 \%$. RF in cutting mode if used inappropriately can give rise to bleeding issue otherwise not $[1,2]$.

\section{Conclusion}

RF appears to be an efficient tool for snoring/sleep apnoea procedures because of

Ability to cut fast and maintain a relatively bloodless field 
Ability to cut and coagulate at various settings

Decrease intraoperative blood loss.

Induces fibrosis and stiffening of tissues

Decrease postoperative pain

\section{Other advantages}

The instrument / unit appears DYNAMIC WITH A GOOD UNIQUE FEEL.

PROCEDURES CAN BE PERFORMED UNDER LOCAL / GEN. ANAESTHESIA

INSTRUMENTS ARE AUTOCLAVABLE/RECURRING COST IS LOWER

MACHINE IS AMBULATORY

Minimally invasive

\section{References}

1. Steward DL. Methods and outcomes of radiofrequency ablation for obstructive sleep apnoea. Operative Techniques in Otolaryngology. 2006; 17: 233-237. Ref.: http://bit.ly/2K7aT2L

2. Pang KP, Blanchard AR, Terries DJ. Surgical treatment of sleep disordered breathing. Department of otolaryngology, TanTock Sengh hospital Singapore and Dept. of otolaryngology, Medical college of Georgia, Augusta, Georgia, USA. 